\title{
Types of cooking stove and risk of Acute Lower Respiratory Infection among under-five children: a cross sectional study in Rasuwa, a Himalayan district of Nepal
}

\author{
Sharma SR ${ }^{1}$,Bhandari NN², Bhandari $\mathrm{R}^{3}$, Wagle $\mathrm{K}^{4}$, Adhikari $\mathrm{M}^{5}$ \\ ${ }^{2}$ Nitin Nischal Bhandari, Integrated Rural Health Development Training Centre Nepal, Kathmandu, Nepal \\ ${ }^{3}$ Ram Bhandari, Integrated Rural Health Development Training Centre Nepal, Kathmandu, Nepal \\ ${ }^{4}$ Kusum Wagle, Om Health Campus, Kathmandu, Nepal \\ ${ }^{5}$ Mukesh Adhikari, District Health Office, Rasuwa, Nepal
}

\begin{abstract}
Background: In Nepal, about $75 \%$ people rely on wood and other biomass fuels for cooking. The majority of Nepali families cook on a traditional stove, an open fire in the kitchen resulting in indoor air pollution, one of the key risk factors for Acute Lower Respiratory Infection (ALRI) among under-five children. The study aimed at exploring the association of indoor air pollution due to use of traditional cooking stoves with ALRI among under-five children in Rasuwa, a Himalayan district of Nepal.
\end{abstract}

\begin{abstract}
Methods: A cross-sectional survey was conducted in Rasuwa district from October to November 2011. The mothers with under-five children who lived in household using biomass fuels were interviewed. The totalsample size of 210 , calculated on the basis of Proportion to Population Size, was selected by using cluster sampling method. Children who suffered from common cold and fast breathing/higher respiratory rate were defined as having ALRI. Logistic regression was used to find out association of types of cooking stove and other factors with ALRI among the children.
\end{abstract}

Results: Only about $30 \%$ of the households used improved stoves for cooking. Nearly one-third (31.4\%) of the children under five years of age who lived in household using biomass fuels suffered from ALRI. After adjusting for the factors like mother's group status, ethnic group, age of children, mother's group membership status and father's occupation, use of traditional/open type of cooking stove was found to be highly associated with ALRI [aOR:2.30; $95 \%$ $\mathrm{Cl}$ (1.03-5.10)] among children.

Conclusion: Exposure to smoke from a traditional stove is one of the factors leading to ALRI among children. The ALRI could be substantially reduced if these stoves be replaced by improved ones in rural areas of Nepal.

Keywords: Acute Lower Respiratory Infection; stoves; under-five children.

Submitted: 10 December 2014; Revised: 28 February 2015; Accepted: 2 March 2015

\section{Introduction}

According to World Health Organization (WHO), around 3 billion people worldwide use open fires and leaky stoves burning biomass (wood, animal dung and crop waste) and coal to cook and heat their homes (1).Nearly 2 million people die each year from exposureworldwide to cook stove smoke (2). In a study by WHO, indoor smoke is one of the underlying causes resulting nearly 800,000 child deaths annually. Further, inhaling indoor smoke doubles the risk of pneumonia and other acute infections of lower respiratory tract among under-five children which is the single most important child killer globally (3).

The census 2011 report in Nepal shows that about $75 \%$ of households depend upon solid bio-fuels (firewood about $64 \%$ and cow dung about 11\%) for domestic uses (4).
Use of solid bio-fuels is higher in rural areas of Nepal. Majority of Nepali families cook on traditional stoves, mostly in an open fire (5). Burning of solid fuels like biomass and coal on traditional, inefficient stoves or open fires results in indoor air pollution (6-8) which is the major cause of lower respiratory infections (9). In Nepal, Acute Lower Respiratory Infection (ALRI) is one of the major causes of deaths

\section{Correspondence: \\ 'Sudesh Raj Sharma \\ Integrated Rural Health Development Training \\ Centre Nepal \\ Kathmandu, Nepal \\ Email: yoursudesh@gmail.com}


among under-five children (10). Half of the deaths from ALRI among children are due to particulate matters inhaled from household solid fuels (1). Inhaling of indoor smoke from cooking fire using biomass as household fuel increases the risk of ALRI among under-five children (11-14) and thus increases threats of infant mortality and morbidity $(6,15)$. The improved stoves compared to traditional open ones, use less firewood with the smoke outlet away from the house which reduce indoor air pollution and consequently can lower the respiratory problems (5, $16,17)$. The main aim of this study was to explore the association of indoor air pollution due to use of traditional cooking stoves with ALRI among under-five children in Rasuwa.

\section{Methods}

This cross sectional survey was conducted from October to November 2011 in Rasuwa district of central Himalayan region in Nepal. Those households using biomass as cooking fuel were included in the study. Mothers of thehouseholds, having at least one under five children preceding the survey, were interviewed.

Six Village Development Committees (VDCs), out of 18, were randomly selected from the district which represented $33 \%$ of the total VDCs. A 30 by 7 cluster sampling method based on Proportion to Population Size (PPS) was used taking wards (sub-administrative unit of VDC) as clusters (Figure 1). Students with public health background were recruited and trained for data collection. They collected data under supervision of the principal investigator. In the first step, the data collection team met the local leaders of a ward (the cluster) to develop a rough map of the major settlements (sub-clusters) within the ward, often called "toles" in Nepali. The toles were coded randomly as $1,2,3$ and 4 . Starting from 1, in each tole, the field team reached the main settlement and threw a stick to the ground. They then chose the first house for interview towards which the stick was pointing. The researcher followed a pattern (straight or zigzag) to select the other houses for interviews until the desired number of respondents was interviewed. Only in Bhorle VDC, two clusters fell in the same ward due to high number of population. In that case, the ward was virtually divided into two equal halves and above mentioned process was repeated for each cluster. From each cluster, seven respondents were selected for interview and the enumerator moved to next cluster as soon as the target number of respondents for the cluster was met. As expected, the target number of seven respondents was met at each cluster. In case of having more than one mother in the sampled household, only one was selected randomly for interview.

Mothers of selected household were interviewed face to face to collect the information. A structured questionnaire, including observation checklist was developed based on relevant literatures and used for the interview. The developed questionnaire was translated into Nepali language for interview. The questionnaire was pretested among five mothers residing in Dapcha VDC of Kavre district. Few necessary modifications in sequencing, addition and removal of some questions were made prior to data collection. The study was conducted by Integrated Rural Health Development Training Centre (IRHDTC/Nepal) in coordination with District Health Office at Rasuwa as an operational research to strengthen $\mathrm{CBIMCl}$ program. All ethical procedures for a cross sectional study was followed including written informed consent taken before interview.

Fig 1: Flowchart of the sampling process

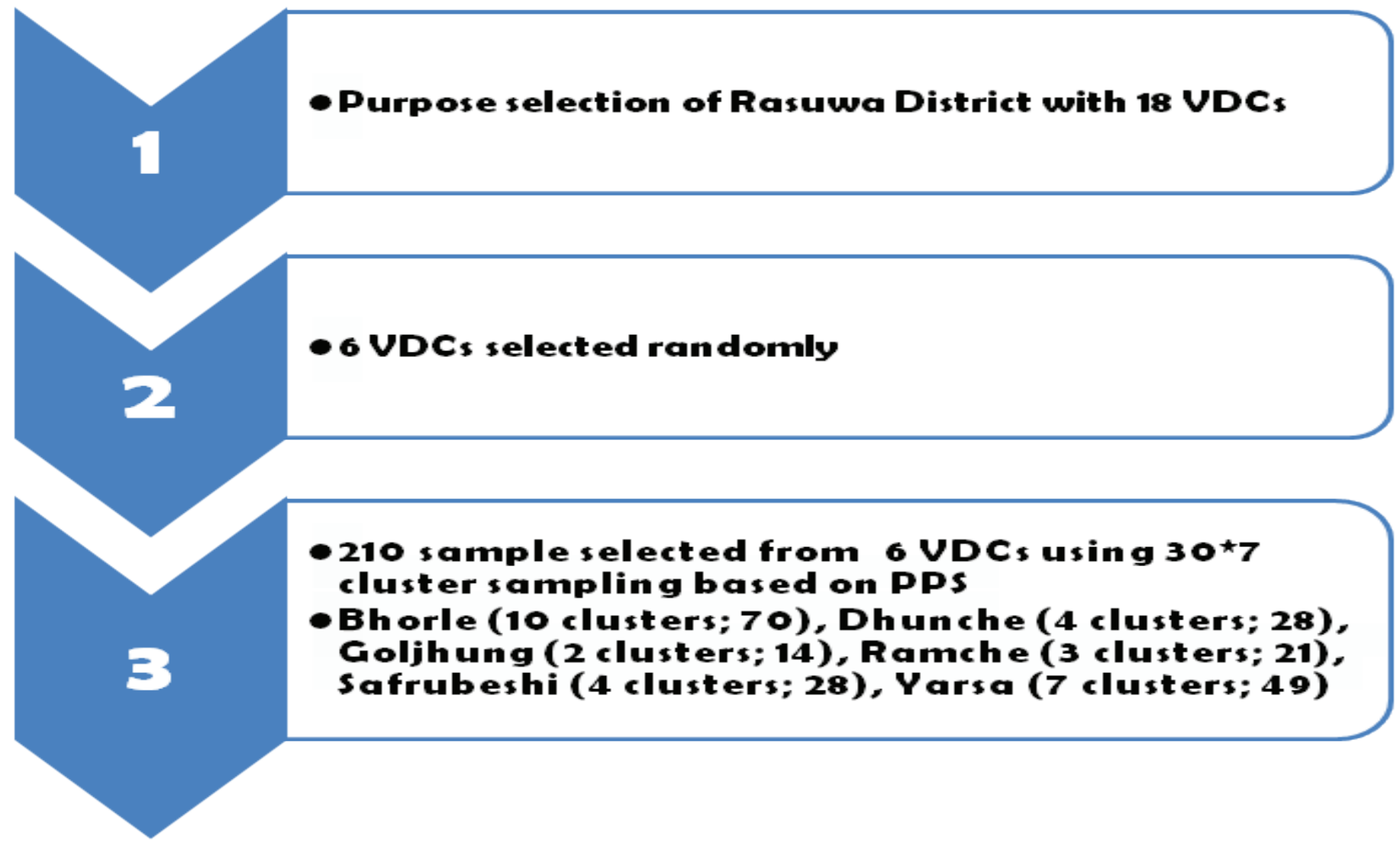


The study did not involve any experimentation or insertion procedures. Study investigators fully respected the right of refusal to participate or stop an ongoing interview anytime.

\section{Outcome variables}

ALRI among under-five children was the outcome variable of the study. Signs and symptoms of under-five child in the selected household were identified and categorized as either having ALRI or not. Respiratory rate is a valuable clinical sign for ALRI diagnosis (18). Mothers were asked if their child had symptoms of common cold with fast breathing within last 30 days. The children with history of common cold and fast breathing or increase in respiratory rate within the last 30 days were defined as having ALRI.

\section{Explanatory variables}

Interview as well as observation was done to explore the types of cooking stove in households. The traditional stoves with open fire tripod releasing high amount of smoke inside the kitchen were classified as open stove whereas modified stoves with smoke outlet out of the house and resulting in less indoor air pollution were classified as improved fire stoves. The socio-demographic factors under this study were ethnicity, age of mother and child, mother's group membership status, occupation and educational level of parents, type of family, and wealth index. The caste was categorized into six ethnic groups namely dalit, disadvantaged janajatis, disadvantaged non-dalit terai caste groups, religious minorities, relatively advantaged janajatis and upper caste group (Brahmin/ Chhetri) according to classification by Health Management Information System of Nepal. These ethnic groups have been divided on the basis of their socio-cultural status (19). For bivariate analysis, they were further grouped into two categories, privileged ethnic group including upper caste and relatively advantaged janajatis and nonprivileged group including relatively disadvantaged janajatis and dalits. The age of mother was grouped into two categories as less than 20 and 20 years or more. The age of children was categorized into less than 12 months and 12 months or more. In every ward, Female Child Health Volunteers (FCHVs) provide health awareness programs on prevention and management of childhood illness through mothers' group meeting. Hence, mothers' group membership was studied that signifies their participation in such programs and that can affect their awareness and practices on ALRI. Occupation of mothers and fathers were grouped into either labour intensive or non-labour intensive on the basis of type of work. Labour intensive occupation included works in restaurants, hotels, agriculture, mining, construction sites and so on that required more physical works with comparatively less wages. The labour intensive groups can have fewer chances of well household economy, educational level and proper care of their children. The educational level of parents were categorized into illiterate and literate (just literate, primary and above). The wealth index was classified into three ranked categories in terciles. Terciles were calculated using Principle Component Analysis functionality of SPSS. The categorization process was similar to that of wealth quintile in Demographic Health Survey (20). In this research, however, wealth index was categorized into only three groups due to small sample size. First tercile comprised of the group with relatively low aggregate wealth, second tercile comprised of the group with relatively average aggregate wealth and third tercile comprised of the group with relatively high aggregate wealth.

\section{Data analysis}

The filled questionnaires were checked, edited and coded systematically immediately after data collection. Data were then entered into Epi info (3.5.1 version). The data were imported into Statistical Package for Social Sciences (SPSS) version 17 and logistic regression was applied for analysis. The significantly associated variables at $p$-value less than 0.05in bivariate analysis were evaluated in multivariate logistic analysis at $95 \%$ level of significance.

\section{Results}

Table 1 represents the characteristics of respondents under study. Majority of the households (69.5\%) used open stoves and the remaining (30.5\%) used improved stoves for cooking purpose. About one in three (31\%) under-five children had ALRI within last 30 days of data collection. The highest number of respondents was from Bhorle VDC followed by Yarsa VDC and the least was from Goljhung VDC. Majority of the respondents (69\%) belonged to disadvantaged janajatis and about $30 \%$ of the mothers had child aged less than 12 months. Most of the mothers were aged 20 and above. Most (59\%) of the mothers were not affiliated to their local mother's group. A higher proportion of the mothers (90\%) and fathers $(79.5 \%)$ were involved in labor intensive works. Out of total, $57 \%$ of mothers and $36 \%$ of fathers were illiterate and $53 \%$ of the respondents were from joint families.

\section{Factors associated with the ALRI}

In the bivariate analysis, types of cooking stove, ethnicity, age of child, age of mother, mothers' group membership status and occupation of father were independently associated with ALRI among under-five children as in Table 2. The significant factors were then subjected to multivariate logistic regression analysis. Open type of cooking stove was found to be highly associated with ALRI [aOR-2.30; $95 \% \mathrm{Cl}(1.03-5.10)]$ in under five children after controlling for possible confounders i.e. caste group, age of children, mother's group membership status and occupation of father (Table 3). Younger age of child (less than 12 months) [aOR-1.78; 95\% Cl (0.91-3.48)] and labour intensive occupation of father [aOR-2.4; 95\% Cl (0.9-6.44)] were also found to be significantly associated with ALRI (Table 3).

\section{Discussion}

Majority of the people (69.5\%) from Rasuwa used traditional open fire stoves for cooking. Another study conducted in five VDCs of the district stated that more than $90 \%$ of households in the area depend on biomass fuel for cooking as well as heating homes and most of them use inefficient traditional stoves in poorly ventilated kitchens (12). Census 2011 showed that about $90 \%$ of the households in Rasuwa use wood/firewood for cooking (4). 
Table 1: Type of PPE used $(n=163)$

Characteristics

Frequency

Percentage

Types of cooking stove

Improved stove

64

30.5

Open stove

146

69.5

Child suffering from common cold and fast breathing in last $\mathbf{3 0}$ days

Yes

65

31.4

No

145

68.6

Name of the VDC

Bhorle (SHP) 70

33.3

Dhunche (HP) 28

13.3

Goljhung (SHP) 14

6.7

Ramche (SHP) 21

10.0

Syafrubesi (HP) 28

13.3

Yarsa (SHP)

23.3

Ethnicity

Dalit

Disadvantaged janajati

Age of child (in months)

$$
<12
$$

24-60

Age of the mother (years)*

$<20$

$\geq 20$

MGM membership status

Yes

No

Occupation of mother

Labour intensive

Non-labour intensive

Occupation of father

Labour intensive $\quad 167$

79.5

Non-labour intensive

Education level of mother

Illiterate

Just literate

Primary

Secondary

Certificate level

Bachelor

Education level of mother

Illiterate

Just literate

Primary

Secondary

Certificate level

Bachelor

Type of family

Nuclear $\quad 94$

Joint

Wealth index 
Table 2: Bivariate analysis of various characteristics of the respondents and ALRI

\begin{tabular}{|c|c|c|c|c|c|}
\hline \multirow[t]{2}{*}{ Characteristics } & \multicolumn{2}{|c|}{ ALRI in last 30 days } & \multirow[t]{2}{*}{ Crude OR } & \multirow[t]{2}{*}{$95 \% \mathrm{Cl}$} & \multirow[t]{2}{*}{ p-value } \\
\hline & Yes & No & & & \\
\hline \multicolumn{6}{|l|}{ Types of cooking stove } \\
\hline Open stove & 54 & 92 & 2.83 & $1.36-5.87$ & 0.004 \\
\hline Improved stove & 11 & 53 & & & \\
\hline \multicolumn{6}{|l|}{ Ethnic groups } \\
\hline Underprivileged & 52 & 96 & 2.04 & $1.01-4.10$ & 0.043 \\
\hline Privileged & 13 & 49 & & & \\
\hline \multicolumn{6}{|l|}{ Age of children } \\
\hline$<12$ months & 25 & 36 & 1.89 & $1.01-3.53$ & 0.044 \\
\hline $\begin{array}{l}\geq 12 \text { months } \\
\text { Age of mother }\end{array}$ & 40 & 109 & 1.00 & & \\
\hline$<20$ years & 7 & 4 & 4.19 & $1.18-14.88$ & \\
\hline$\geq 20$ years & 58 & 139 & 4.19 & $1.10-14.00$ & $0.109^{a}$ \\
\hline \multicolumn{6}{|c|}{ Mother's group membership status } \\
\hline No & 45 & 79 & 1.88 & $1.01-3.49$ & 0.045 \\
\hline \multirow{2}{*}{\multicolumn{6}{|c|}{ Occupation of mother }} \\
\hline & & & & & \\
\hline Labour intensive work & 61 & 130 & 1.76 & $0.56-5.52$ & 0.328 \\
\hline Non-labour intensive work & 4 & 37 & & & \\
\hline \multicolumn{6}{|l|}{ Occupation of father } \\
\hline Labour intensive work & 52 & 108 & 3.37 & $1.34-8.45$ & 0.007 \\
\hline Non-labour intensive work & 13 & 37 & & & \\
\hline \multicolumn{6}{|l|}{ Education of mother } \\
\hline Illiterate & 42 & 78 & 1.57 & $0.86-2.87$ & 0.143 \\
\hline Literate & 23 & 67 & & & \\
\hline \multicolumn{6}{|l|}{ Education of father } \\
\hline $\begin{array}{l}\text { Illiterate } \\
\text { Literate }\end{array}$ & $\begin{array}{l}26 \\
39\end{array}$ & $\begin{array}{l}49 \\
96\end{array}$ & 1.31 & $0.71-2.39$ & 0.385 \\
\hline \multicolumn{6}{|l|}{ Type of family } \\
\hline Nuclear & 29 & 65 & 0.99 & $0.55-1.786$ & 0.977 \\
\hline $\begin{array}{l}\text { Joint/Extended } \\
\text { Wealth index }\end{array}$ & 36 & 80 & & & \\
\hline $\begin{array}{l}\text { Weaith Index } \\
\text { First (poor) }\end{array}$ & 18 & & & & \\
\hline Second & $\begin{array}{l}18 \\
19\end{array}$ & $\begin{array}{l}52 \\
51\end{array}$ & 1.93 & $0.94-3.95$ & 0.074 \\
\hline Third (least poor) & 28 & 42 & 1.79 & $0.88-3.64$ & 0.109 \\
\hline
\end{tabular}

Table 3: Multivariate analysis of factors associated with ALRI

\begin{tabular}{|c|c|c|c|c|c|c|}
\hline \multirow[t]{2}{*}{ Characteristics } & \multicolumn{2}{|c|}{$\begin{array}{c}\text { ALRI in } \\
\text { last } 30 \text { days }\end{array}$} & \multirow[t]{2}{*}{$\begin{array}{l}\text { Crude OR } \\
\text { (95\% CI) }\end{array}$} & \multirow[t]{2}{*}{ p-value } & \multirow[t]{2}{*}{$\begin{array}{l}\text { Adujusted OR } \\
\qquad(95 \% \mathrm{Cl})\end{array}$} & \multirow[t]{2}{*}{$p$-value } \\
\hline & Yes & No & & & & \\
\hline \multicolumn{7}{|l|}{ Types of cooking stove } \\
\hline Open stove & 54 & 92 & $2.83(1.36-5.87)$ & 0.004 & $2.30(1.03-5.10)$ & 0.040 \\
\hline Improved stove & 11 & 53 & & & & \\
\hline \multicolumn{7}{|l|}{ Age of children } \\
\hline$<12$ months & 25 & 36 & $1.89(1.01-3.54)$ & 0.044 & $1.78(0.91-3.48)$ & 0.092 \\
\hline$\geq 12$ months & 40 & 109 & & & & \\
\hline \multirow{3}{*}{$\begin{array}{l}\text { Occupation of father } \\
\text { Labour intensive work } \\
\text { Non-labour intensive work }\end{array}$} & 59 & & & & & \\
\hline & 6 & 108 & 3.37 (1.34-8.45) & 0.007 & $2.40(0.90-6.44)$ & 0.083 \\
\hline & & 37 & & & & \\
\hline
\end{tabular}


Out of total, $31.4 \%$ of under-five children suffered from ALRI in the study area. This indicates that ALRI is one of the major health problems of children in the district. After adjustment of confounding factors, the type of stoves was found to be associated significantly with having ALRI among the children. Children from households using traditional open fire stoves were more than twice likely to suffer from ALRI. Many other studies depicted that children living in household that uses solid fuel as their primary cooking fuel have higher risk of $A R I$ in comparison to those using cleaner fuels $(21,22)$. A study in Dhading district of $\mathrm{Ne}$ pal computed that about $50 \%$ of Disability Adjusted Life Years (DALYs) lost due to ARI and pneumonia were attributed to indoor smoke (15). High prevalence of acute respiratory infection among children was associated with the use of such unprocessed biomass fuels in traditional open stoves (23). There was significant increase in risk of ALRI among young children who were exposed to indoor smoke from solid fuels $(24,25)$ and improved stoves in community have been effective in reducing child exposure to the indoor smoke $(2,26)$. A study by Smith et al. stated that improved cook stoves with lower exposure than the traditional ones might be needed to reduce ALRI substantially (27).

The present study further depicted that smaller the age of child, the higher the risk of having ALRI due to indoor smoke. Younger child are at risk of respiratory diseases since they are more often carried on mother's back while cooking and get exposed to indoor air pollution (28). Interestingly, occupation of father was also found to be linked with ALRI which might be associated with the affordability and awareness regarding the use of improved stove. Labour intensive jobs are usually low paid which may be limiting the capacity of corresponding families to afford improved stoves. Use of traditional/open stoves causing indoor air pollution is strongly linked with poverty (29). Poor families tend to be less educated and unaware about key health issues including indoor air pollution and its effects on children. Local health organizations can help in improving awareness about risks of using traditional stoves particularly among poorer groups.

Although this study possesses the strength such as cluster random sampling, pre-tested structured questionnaire and direct observation technique for data collection, it had some limitations as well. Results might have been affected by recall bias. The study was limited to only Rasuwa district due to which the findings should be used carefully for comparing with evidences from other (Hill and Terai) parts of the country. Variables such as smoking habit of parents and location of cooking stoves in houses, that could be associated with ALRI, were not explored. Future studies addressing these factors can provide clearer picture on the associated factors of ALRI.

\section{Conclusion}

This study concluded that the use of traditional open types of cooking stoves was significantly associated with prevalence of ALRI among under-five children. Thus, use of improved cooking stove is recommended to prevent ALRI in children. Cost-effective improved cook stove program might be promoted targeting the rural and poor households in colder regions of Nepal to decrease the incidence of ALRI among under-five children in future. Further, the District Health Office could prioritize child health promotion programs in those areas where there is high use of traditional cooking stoves.

\section{Acknowledgment}

Authors would like to acknowledge the participants of the study and staff of Integrated Rural Health Development Training Centre who supported us during data collection.

\section{Authors' contribution}

SRS and NNB conceived and designed the study. SRS, NNB and MA performed the study supervised by RB. SRS and $\mathrm{KW}$ analyzed the data and prepared the manuscript. NNB, RB and MA critically revised the manuscript. All authors read and approved the final manuscript.

\section{References}

1. World Health Organization. Indoor air pollution and health.2011. Available from: http://www.who.int/mediacentre/factsheets/fs292/en/.

2. Global Alliance for Clean Cookstoves. [Internet]. Available from: http:// www.unfoundation.org/assets/pdf/global-alliance-for-clean-cookstovesfactsheet.pdf.

3. Rehfuess E. World Health Organization. Fuel for life : household energy and health. 2006.

4. Central Bureau of Statistics. National Population and Housing Census, 2011. National Planning Commission, Government of Nepal; 2012.

5. EWB-UK Bursary Report [Internet]. 2007. Available from: http://www. ewb-uk.org/system/files/EWB-UK+Bursary+Report+(Nigel+Vaz)_0.pdf.

6. Sustainable Energy Solutions to Reduce Poverty in South Asia MANUAL- [Internet]. Available from: http://www.inforse.org/asia/M_III stoves.htm.

7. Smith KR, Mehta S. The burden of disease from indoor air pollution in developing countries: comparison of estimates. International journal of hygiene and environmental health. 2003;206(4-5):279-89.

8. Rehfuess EA, Bruce NG, Smith KR. Solid Fuel Use: Health Effect. Nriagu JO (ed) Encyclopedia of Environmental Health. Burlington: Elsevier.2011. p. 150161.

9. Fuentes-Leonarte V, Ballester F, Tenias JM. Sources of indoor air pollution and respiratory health in preschool children. Journal of environmental and public health. 2009;2009:727516.

10. Ministry of Health and Population NE, ICF International Inc. Nepal,. Nepal Demographic and Health Survey 2011. Kathmandu, Nepal: Ministry of Health and Population, New ERA, and ICF International, 2012.

11. Armstrong JR, Campbell $\mathrm{H}$. Indoor air pollution exposure and lower respiratory infections in young Gambian children. International journal of epidemiology. 1991;20(2):424-9.

12. Thakuri MBM. Why Tackling Indoor Air Pollution Makes Sense - A Study from Nepal. 2009.

13. Bates MN, Chandyo RK, Valentiner-Branth P, Pokhrel AK, Mathisen $\mathrm{M}$, Basnet $\mathrm{S}$, et al. Acute lower respiratory infection in childhood and household fuel use in Bhaktapur, Nepal. Environmental health perspectives. 2013;121(5):637-42.

14. Bautista LE, Correa A, Baumgartner J, Breysse P, Matanoski GM. Indoor charcoal smoke and acute respiratory infections in young children in the Dominican Republic. American journal of epidemiology. 2009;169(5):572-80. 
15. Dhimal M, Dhakal P, Shrestha N, Baral K, Maskey M. Environmental burden of acute respiratory infection and pneumonia due to indoor smoke in Dhading. Journal of Nepal Health Research Council. 2010;8(1):1-4.

16. Rana L. Improved Stove. The Farmers' Handbook - "Inside The House".

17. Nepal M, Nepal A, Grimsrud K. Which Type of Stove is Best? An Environmental Impact Assessment from Nepal. 2010.

18. Simoes EAF, Cherian T, Chow J, Shahid-Salles SA, Laxminarayan R, John TJ. Acute Respiratory Infections in Children. Disease Control Priorities in Developing Countries,2006. p. 484-97.

19. Bhandari R, Sharma R. Epidemiology of chronic obstructive pulmonary disease: a descriptive study in the mid-western region of Nepal. International Journal of Chronic Obstructive Pulmonary Disease.

2012;7:253-7.

20. Rutstein SO, Johnson K. The DHS Wealth Index. DHS Comparative Reports No. 6. Calverton, Maryland: ORC Macro, 2004.

21. Mishra V. Indoor air pollution from biomass combustion and acute respiratory illness in preschool age children in Zimbabwe. International journal of epidemiology. 2003;32(5):847-53.

22. Acharya P, Mishra SR, Berg-Beckhoff G. Solid Fuel in Kitchen and Acute Respiratory Tract Infection Among Under Five Children: Evidence from Nepal Demographic and Health Survey 2011. Journal of community health. 2014.

23. Joshi SK. Solid biomass fuel: Indoor air pollution and health effects Kathmandu University medical journal. 2006;2(14):141-2.
24. Smith KR, Samet JM, Romieu I, Bruce N. Indoor air pollution in developing countries and acute lower respiratory infections in children. 2000;55(6):518-32.

25. Dherani M, Pope D, Mascarenhas M, Smith KR, Weber M, Bruce $N$. Indoor air pollution from unprocessed solid fuel use and pneumonia risk in children aged under five years: a systematic review and metaanalysis. Bulletin of the World Health Organization. 2008;86(5):390-8C.

26. Bruce N, McCracken J, Albalak R, Schei MA, Smith KR, Lopez V, et al. Impact of improved stoves, house construction and child location on levels of indoor air pollution exposure in young Guatemalan children. Journal of exposure analysis and environmental epidemiology. 2004;14 Suppl 1:S26-33

27. Smith KR, McCracken JP, Weber MW, Hubbard A, Jenny A, Thompson LM, et al. Effect of reduction in household air pollution on childhood pneumonia in Guatemala (RESPIRE): a randomised controlled trial. Lancet. 2011;378(9804):1717-26.

28. O'Dempsey TJD, McArdle TF, Morris J, Lloyd-Evans N, I B, Laurence BE, et al. A Study of Risk Factors for Pneumococcal Disease among Children in a Rural Area of West Africa. International journal of epidemiology. 1996;25(4):885-93.

29. Emmelin A, Wall S. Indoor air pollution: a poverty-related cause of mortality among the children of the world. Chest. 2007;132(5):1615-23. 